\title{
Erratum to: When Gumbel met Galambos
}

\section{Christian Genest and Johanna G. Nešlehová}

\section{Erratum to:}

Chapter 6 in: M. Úbeda Flores et al. (eds.), Copulas and Dependence Models with Applications, https://doi.org/10.1007/978-3-319-64221-5_6

This chapter was originally published under (C) Springer International Publishing AG 2017, but has now been republished under (C) The Author(s). 